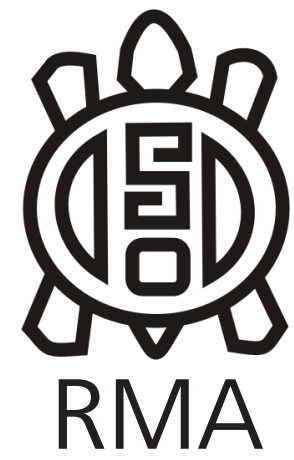

Arqueología

\title{
Alfarería del prehispánico Tardío en las quebradas altas del Calchaquí (Salta): una primera aproximación a los estudios de pastas de Tacuil y Gualfín
}

\author{
Late prehispanic pottery in the high ravines of Calchaqui (Salta): a first \\ approximation to the pastes studies of Tacuil and Gualfín
}

*Instituto de las Culturas, Universidad de Buenos Aires, CONICET, Argentina. E-mail: cecicastellan88@yahoo.com.ar **Instituto de Investigaciones en Energía No Convencional, Universidad Nacional de Salta, CONICET, Facultad de Ciencias Naturales, Argentina. E-mail: fatima2690@gmail.com ***Instituto GEONORTE, Universidad Nacional de Salta, CONICET, Facultad de Ciencias Naturales. E-mail: geoalex656@gmail.com

\begin{abstract}
Resumen
Se presenta información de una muestra de alfarería recuperada en asentamientos de las quebradas altas del valle Calchaquí, provincia de Salta. Los conjuntos analizados provienen de excavaciones y recolecciones de superficie realizadas en el Fuerte de Tacuil y Gualfín, y en los recintos bajos asociados a los mismos. Asentamientos que presentan ocupaciones que fueron fechadas mediante dataciones radiocarbónicas entre, por lo menos, los años 1200 y 1600 dC. Se realizaron caracterizaciones de pastas cerámicas a nivel submacroscópico y microscópico integrando datos de los análisis estilísticos. Los resultados alcanzados permiten proponer, a manera de hipótesis, una producción local de alfarería en la zona, una variabilidad a nivel tecnológicolestilístico y una circulación de ciertos estilos, durante momentos del Período de Desarrollos Regionales e Inca, que llevó a sugerir la participación de las poblaciones de las quebradas altas en circuitos de interacción que incluían sectores aledaños a Calchaquí, como la actual puna de Catamarca.
\end{abstract}

Palabras clave: Valle Calchaquí; Período de Desarrollos Regionales e Inca; Pukaras; petrografía cerámica

\begin{abstract}
The information presented of a pottery sample is recovered from settlements in the high ravines of the Calchaqui Valley, Salta province. The analyzed set belongs to excavations and surface collections, which were carried out in the Fort of Tacuil and Gualfin, and in the low enclosures associated with it. Settlements that present occupations that were dated by radiocarbon dating between, at least, the years 1200 y 1600 BC. Characterization of pastes was carried out at the microscopic level and using a loupe, integrating data from the stylistic analysis. The results obtained allow proposing, as a hypothesis, a local production of pottery in the area, a variability at the technological and stylistic level and circulation of certain styles during the period of the Regional and Inca Development Period. It leads us to suggest the participation of the high ravines' populations in interaction circuits that included the surrounding sectors of the Calchaquí Valley, as the current puna of Catamarca.
\end{abstract}

Key words: Middle Valle Calchaqui; Latter prehispanic period; Pukaras; Petrography of pottery.

El valle Calchaquí, en la actual provincia de Salta, Noroeste Argentino (en adelante NOA), constituyó un importante espacio de circulación a lo largo de la historia. Datos históricos, etnográficos y arqueológicos dan cuenta de ello (García et al. 2002; Sprovieri 2014; Villegas 2014). Se ha sugerido que durante el Período de Desarrollos Regionales (PDR) o Tardío, cerca del 900 al 1400 DC, las sociedades del valle presentaban una fuerte articulación con espacios como el valle de Yocavil, la región puneña y las yungas (Sprovieri 2014).
Las investigaciones arqueológicas realizadas en un sector comprendido entre las cuencas de Angastaco y Molinos, sobre las quebradas laterales al valle central, señalan la importancia de las mismas como nexos naturales con la Puna (Baldini 2003; Villegas 2011; Williams 2010). Aquí se destaca la presencia de asentamientos de tipo pukara ${ }^{1}$,

\footnotetext{
1 Seguimos la noción de pukara propuesta por Ruiz y Albeck (1997: 235) para hablar de un asentamiento elevado naturalmente protegido y de acceso dificultoso, con gran visibilidad
} 
que presentan una ocupación que va desde el PDR hasta mediados del siglo XVII (Villegas 2014; Williams 2010).

En el NOA, este tipo de asentamientos se localiza a lo largo de la cordillera oriental y occidental controlando cabeceras de valles y cuencas, también en zonas de fronteras internas que marcaban límites entre organizaciones sociopolíticas (Ruíz y Albeck 1997; Tarragó 2000). Para el altiplano andino, los mismos son característicos para el Intermedio tardío (entre aproximadamente el 900 y 1400 DC). En particular desde la segunda mitad (cerca del 1300 DC), un período de conflicto social generalizado donde se sucedieron además eventos de inestabilidad climática que pudieron afectar la vida de las poblaciones generando modificaciones en los patrones de asentamientos como también en las relaciones y redes de interacción (Arkush 2012; Nielsen 2007).

En este trabajo presentamos información sobre una muestra de cerámica procedente de asentamientos de tipo pukara del valle Calchaquí y de recintos bajos asociados a los mismos. La misma fue recuperada mediante excavaciones y prospecciones pedestres y analizada desde un enfoque tecnológico y composicional, a nivel submacroscópico y microscópico, y cruzando estos datos con los estilos cerámicos reconocidos para la zona?

\section{Las cuencas de Angastaco y Molinos durante el Período de Desarrollos Regionales e Inca desde la arqueología}

Para el sector medio del valle Calchaquí, Baldini (2003) señala la existencia de ocupaciones que presentan características propias del Tardío o PDR y la relevancia de las cuencas occidentales subsidiarias al valle troncal como nexos de comunicación natural entre valles y puna, destacando notables diferencias entre las ocupaciones fondo de valle y las de sus quebradas laterales. Esto llevó a sugerir que los centros de producción y focos poblacionales se hallarían hacia el interior de las quebradas que comunican con la puna (Villegas 2011: 70). Se planteó que la ocupación de asentamientos conglomerados en esta área se habría dado hacia los siglos IX-X DC y que para momentos posteriores se produjo una concentración poblacional sobre el valle principal (Baldini y Villamayor 2007). Los sitios de mayor envergadura se localizan en los ingresos hacia las quebradas occidentales, permitiendo sugerir que el patrón de asentamientos de estas cuencas presentaba un carácter rural, compuesto por escasos poblados concentrados, estructuras defensivas y amplias extensiones agrícolas (Baldini y Villamayor 2007: 37). Desde la información histórica se ha postulado la presencia de distintas unidades étnicas a la llegada de los españoles al valle, lo que llevó a plantear a este

de su entorno. Este tipo de asentamiento se han popularizado durante el Intermedio Tardío o PDR para los Andes circumpuneños (Ruiz y Albeck 1997).

${ }^{2}$ Nos referimos a estilos definidos para el PDR o Tardío. sector como un espacio multiétnico (Lorandi y Boixadós 1987-88).

Las investigaciones arqueológicas realizadas en este sector del valle destacan la existencia de al menos diez pukara distribuidos en una superficie de 149 ha $\left(1,49 \mathrm{~km}^{2}\right)$ (Williams 2010). De ellos, nueve presentan ocupación desde el Tardío local y uno es de momentos incaicos (Figura 1). Los asentamientos tardíos se hallan en sectores altos, naturalmente defendidos y superando en ocasiones los $200 \mathrm{~m}$ por sobre el nivel de fondo de valle, siendo algunos de ellos de acceso extremadamente difícil por una sola ruta que podía haber sido fácilmente defendida (Cremonte y Williams 2007; Villegas 2014). La localización de los pukara junto a su disposición e intervisibilidad permitió plantear la hipótesis de que, en caso de ser contemporáneos entre sí, podrían haber estado ligados al control del territorio (Villegas 2011: 73; Williams et al. 2005: 342).

La asociación entre pukara y sectores agrícolas en las quebradas altas ha llevado a proponer que los primeros estarían custodiando las áreas más fértiles y posiblemente las vías de comunicación con el ambiente puneño (Villegas 2014). En los campos agrícolas se destacan estructuras para el manejo del agua y grandes bloques rocosos con grabados abstractos, horadaciones o depresiones circulares u ovoidales, representaciones tipo chacras o miniaturas de campos de cultivo, diseños con forma de tumi y ancoriformes (Williams y Villegas 2013: 246). Por otro lado, la gran cantidad de campos agrícolas registrados hacia el interior de estas quebradas ha llevado a plantear la posibilidad de que los mismos hayan sido parte de una política estatal que pudo haber actuado a través de la intensificación de la producción acondicionando grandes extensiones para cultivo, construyendo estructuras de almacenamiento y asentamientos estatales, trabajados por mano de obra local como una forma de tributación agrícola organizada como prestación rotativa de trabajo o por mano de obra especializada (Williams et. al 2010: 182).

La presencia inca en el Calchaquí medio se hace evidente a través del emplazamiento de seis asentamientos con arquitectura imperial en el valle troncal como en el piso de puna, disminuyendo en asentamientos locales y áreas productivas (Villegas 2014; Williams et. al 2010). Sobre el valle troncal encontramos el Pukara y Tambo de Angastaco, donde las excavaciones realizadas en dos estructuras del Tambo han permitido recuperar material cerámico de filiación inca alcanzando más del $50 \%$ del total de fragmentos, además de estilos como el inca Pacajes y el Yavi-chicha en porcentajes menores al 1\% y cerámica de estilo Santa María en un 20\% (Williams et al. 2005).

Hacia el interior de las quebradas altas se localiza el Tambo Gualfín, sitio conformado por estructuras cuadrangulares 
y rectangulares y asociado a un tramo del camino Inca de tipo despejado (Villegas 2014). Este asentamiento, al igual que el resto de los sitios Incas de las quebradas altas, está alejado de los focos de población local pero en una posición estratégica pudiendo tener un control visual del paso hacia el Este y el Oeste (Villegas 2014). Otros asentamientos con arquitectura inca en la zona son Amaicha II sobre el valle del río del mismo nombre (Raffino y Baldini 1983) y las celdas de Gualfín 1 y 2 en el sector alto de la quebrada del río Gualfín (Villegas 2014; Williams 2010). En el ambiente de puna se emplaza el sitio de Compuel el cual presenta estructuras de tipo celdas asociados a un RPC (UGA 5943: 430 25 AP, RPC1, nivel 2) (Williams 2019). Su ubicación estratégica permite tener un control de caminos que comunican zonas como el sector sur del Salar de Atacama o el Alto Loa, la puna catamarqueña y los valles mesotermales de Angastaco (Villegas 2014).

Los estudios sobre alfarería del Tardío o PDR en el valle Calchaquí son escasos en comparación con zonas aledañas como, por ejemplo, el valle de Yocavil. Para el sector norte del valle contamos con trabajos que realizan caracterizaciones morfológicas y estilísticas, además de proponer una secuencia tipológica (Calderari 1991, 1992; Pollard 1983). Sumado a ello, Pollard (1983) también realiza las primeras caracterizaciones petrográficas sobre muestras de alfarería del PDR o Tardío. Trabajos posteriores toman a la alfarería para abordar discusiones en torno a la complejidad social y a cambios/continuidades en las practicas a lo largo de momentos prehispánicos y coloniales tempranos (por ejemplo, Acuto et al. 2011).

Específicamente centrándonos en el sector que analizamos se destacan las primeras menciones que realizan Cigliano y Raffino (1975) sobre una muestra cerámica de Tacuil, Raviña y colaboradores (1983) sobre cerámica del Fuerte de Gualfín, las caracterizaciones de alfarería del sitio El Churcal (Raffino 1984). Para el pukara de Pueblo Viejo, en las quebradas altas, Arechaga (2011) observa cerámica Santa María con diseños geométricos, fragmentos de "urnas lloronas" (Serrano 1976 [1958]) características de la subtradición Calchaquí, fragmentos de vasos libatorios con modelados en el borde y de cerámica Santamariana Valle Arriba.

Se ha mencionado también la presencia de las urnas de tres cinturas como una de las formas típicas del norte y centro del valle Calchaquí (Baldini 1980). Otro estilo cerámico propio del PDR e Inca en los valles Calchaquí, Lerma y quebrada del Toro es la alfarería negra pulida del Tardío (Baldini y Sprovieri 2009). Finalmente, se ha realizado una caracterización estilística a partir de la observación de particularidades a nivel regional e interregional en urnas de estilo Santa María del sector medio del valle (Baldini y Sprovieri 2014).

Debemos destacar, sin embargo, que los trabajos sobre pastas cerámicas son escasos, contando hasta el momento sólo con un antecedente para cerámica de los sitios Molinos I y San Isidro, sobre el valle troncal (Baldini y Balbarrey 2004). A partir de ello, ratifican diferencias, que habían observado a nivel formal y decorativo, entre la alfarería Molinos y la Santa María. Plantean que esta última, en algunos sitios del sector medio del valle, presentaría evidencias de vinculación con "entidades socioculturales algo más tempranas a través de la presencia de alfarería del tipo de Molinos I" (Baldini y Balbarrey 2004: 1080).

\section{Los Fuertes y recintos bajos de Tacuil y Gualfín}

El Fuerte o pukara de Tacuil se ubica en una quebrada lateral de la vertiente occidental del valle Calchaquí en
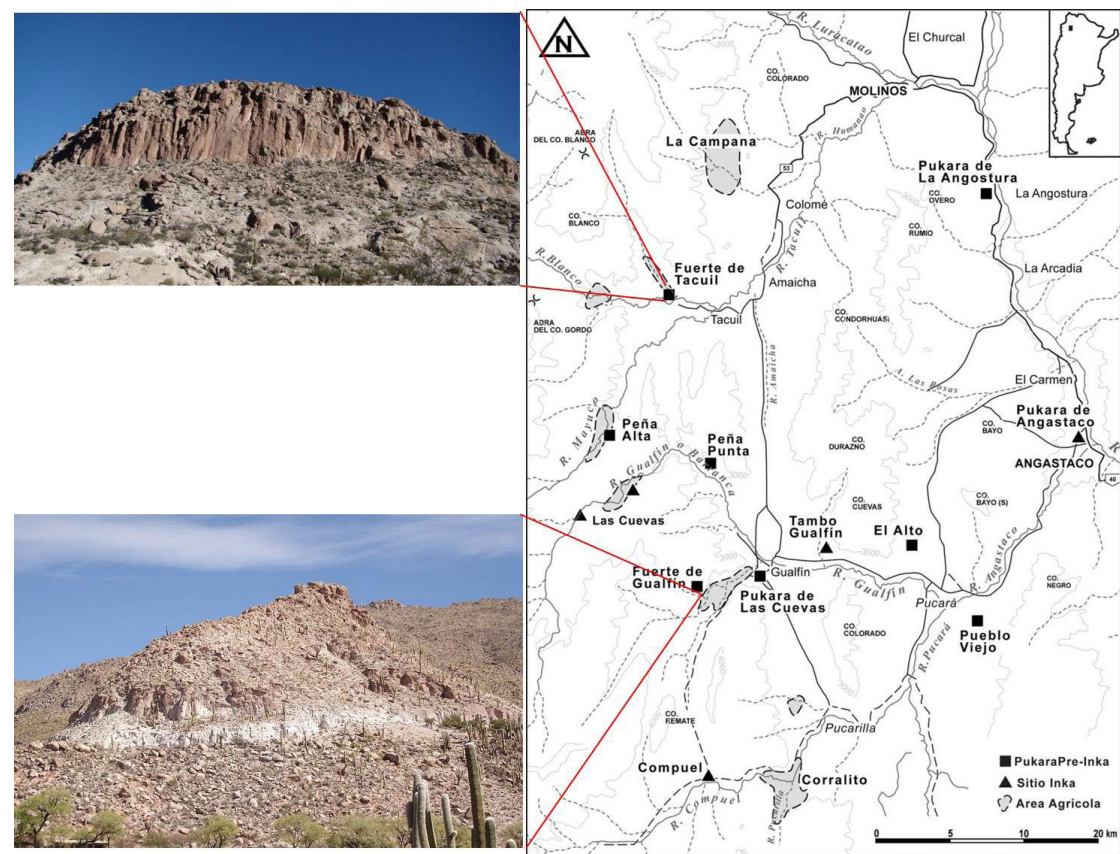

Figura 1. Mapa de ubicación del área de trabajo. Imágenes de los pukara de Tacuil y Gualfín. Imagen modificada de Villegas (2014).

Figure 1. Location map of the work area. Images of the pukara of Tacuil and Gualfín. Image modified from Villegas (2014). 
el Departamento de Molinos, a 2534'17,9' latitud Sur y 66²8'30,6"' longitud Oeste y a $35 \mathrm{~km}$ del pueblo homónimo (Cigliano y Raffino 1975). Es el pukara más septentrional del área de estudio, emplazado sobre una meseta dacítica de origen volcánico que tiene un acceso sumamente difícil y una pendiente de casi $80^{\circ}$ (Cigliano y Raffino 1975: 47). Desde su ubicación se cuenta con un dominio visual sobre la confluencia de los ríos Blanco y La Hoyada, asociados a las abras de los cerros Gordo y Blanco, pasos naturales hacia la puna (Villegas 2011). En la cima se encuentra un conglomerado de estructuras subrectangulares y circulares con muros bien conservados y pasillos, y hacia el Norte de la meseta, restos de, posiblemente, una muralla perimetral (Cigliano y Raffino 1975; Villegas 2014; Williams 2010). Aquí también se hallaron morteros realizados sobre la roca madre, ubicados en sectores protegidos del viento (Williams y Villegas 2013). Al pie del pukara se localizan conjuntos de recintos que fueron denominados como Divisiones arquitectónicas $A$, B y C. En esta ocasión nos referiremos a la cerámica recuperada la División Arquitectónica A (en adelante DAA).

Un fechado radiocarbónico para el fuerte o pukara arrojó una fecha de $630 \pm 25$ AP (UGA 5939), calibrado en $2 \delta$ en 1311-1413 d.C. (OxCal v4.1.7 Bronk Ramsey 2010) (Williams 2019). Para los recintos bajos, se cuenta con tres fechados $590+/-30$ BP (IDA 18C/0767), calibrado en $2 \delta 1290$ - 1420 AD; 760 +/- 30 BP (IDA 18C/0768), calibrado en $2 \delta$ en 1210 - 1290 AD y $610+/-30$ BP (IDA 18C/0769), calibrado en 2 sigma 1290 - 1410 AD (Williams 2019). Hasta el momento no se han registrado evidencias de ocupación inca, a nivel arquitectónico ni material, aunque debemos recordar que Raffino y Cigliano señalan la presencia de escasos fragmentos de cerámica inca (2\% del total de la muestra) (Cigliano y Raffino 1975: 53).

Hacia el sur de Tacuil, y a $50 \mathrm{~km}$ al sudoeste de la actual localidad de Molinos se localizan dos pukaras, un semiconglomerado en fondo de valle y asentamientos agrícolas asociados a los mismos, además de un tambo asociado a tramos de camino Inca (Villegas 2014). Uno de ellos es el del Cerro La Cruz, emplazado sobre un bloque de origen granítico, a 2796 msnm. En la cima se encuentran recintos subcuadrangulares cuya construcción es notablemente expeditiva observándose un mal estado de conservación (Villegas 2014: 96). El segundo es el pukara de Gualfín, emplazado en una meseta ignimbrítica, a $25^{\circ} 46^{\prime} 40,3^{\prime \prime}$ latitud sur y 66 $26^{\prime} 39^{\prime \prime}$ longitud oeste y a una altura de 2984 msnm. Sus construcciones se distribuyen sobre un promontorio de difícil acceso, que domina la quebrada del río Potrerillos. La cercanía que comparten ambos permitió sugerir que podrían haber funcionado de manera conjunta para el control de esta vía de circulación y conexión con la puna (Villegas 2014: 96; Williams y Villegas 2013).
Aquí la mayor concentración de estructuras se localiza sobre la cima y los faldeos norte y oeste. Se ha mencionado también la presencia de murallas semiperimetrales de trazado discontinuo junto con barbacanas rectangulares sobre los faldeos (Raviña et al. 1983: 864). Uno de los rasgos constructivos característicos de este sitio es el aprovechamiento de los afloramientos del cerro, integrando el entorno natural al paisaje construido. Los recintos de la cima no superan los quince, presentando una manufactura mucho más expeditiva que los de la ladera norte, en general con muros simples los cuales se distribuyen según la topografía del lugar de emplazamiento. En el sector norte las estructuras presentan mejor conservación hallándose muros defensivos, recintos con muros dobles y relleno (Villegas 2014: 97; Williams 2010). Hasta el momento contamos con tres fechados para Gualfín; en el caso del pukara arrojó una edad radiocarbónica de $830 \pm 25$ AP, calibrado a $2 \delta$ en 1213-1279 d.C. y para recintos bajos 370 $\pm 40 \mathrm{AP}$, calibrado a $2 \delta$ en 1407-1615 d.C y (OxCal v4.1.7 Bronk Ramsey 2010) (Williams 2019). Para Gualfín, Raviña y colaboradores (1983), sobre una muestra de 280 fragmentos, señalan el predominio de cerámica utilitaria, un $36 \%$ de cerámica de estilo Santa María, además de fragmentos de filiación Inca, Famabalasto negro grabado y Belén inca.

\section{Características geológicas del entorno}

En los alrededores de la localidad de Tacuil se distinguen rocas ígneas, metamórficas y sedimentarias atribuidas a distintas edades geológicas. Las unidades más antiguas (Neoproterozoico-Eocámbrico) que afloran en la región se componen de rocas metamórficas, esquistos, gneises sillimaníticos, metacuarcitas y filitas, que integran el Complejo Metamórfico Rio Blanco y la Formación La Paya; y rocas sedimentarias constituidas por pelitas, grauvacas y areniscas (Formación Puncoviscana). Los esquistos sillimaníticos están compuestos principalmente por cuarzo, biotita, moscovita y sillimanita; adquieren un aspecto bandeado, con folias micáceosillimaníticas y folias cuarzo-feldespáticas. De igual manera, rocas de naturaleza plutónica como granodioritas, monzogranitos, granitos y pegmatitas constituyen los extensos afloramientos cambro-ordovícicos que conforman el Complejo Eruptivo Oire y los granitos Angostura y Pucará (Hongn y Seggiaro 2001).

Los afloramientos del Subgrupo Pirgua de edad crétacica están bien expuestos en los valles de Pucará-Gualfín, en la región de Molinos-Brealito, en el valle de las Cuevas y en ambos flancos del Valle Calchaquí. Estos depósitos sedimentarios están conformados por conglomerados con clastos de granito rosado y pegmatitas, y areniscas arcósicas rojas claras, lutitas verdes amarillentas y grises parduscas (Hongn y Seggiaro 2001). El Fuerte de Tacuil se asienta sobre un depósito de ignimbritas dacitas pliocenas provenientes de la erupción del Cerro Galán o Ignimbrita 
Cerro Galán (Folkes et al. 2011). Esta ignimbrita, en general, se caracteriza por su alto contenido en cristales, con un porcentaje promedio que alcanza el $55 \%$. Es notable el empobrecimiento en pómez que en general no exceden los $2 \mathrm{~cm}$ de diámetro y muy pocos fragmentos lávicos, constituidos en su mayoría por dacitas y andesitas (Folkes et al. 2011).

Los afloramientos del Subgrupo Pirgua están bien expuestos en los valles de Pucará-Gualfín, en la región de Molinos-Brealito, en el valle de las Cuevas y en ambos flancos del Valle Calchaquí. Estos depósitos sedimentarios están conformados por conglomerados con clastos de granito rosado y pegmatitas, y areniscas arcósicas rojas claras, lutitas verdes amarillentas y grises parduscas. En la región de Gualfín, este subgrupo se presenta en pequeñas lomadas ubicadas en la porción central del valle, formado por brechas y conglomerados matriz sostén, de color castaño rojizo, con clastos angulosos de esquistos, cuarzo y pegmatitas. Se intercalan lentes de arenisca fina con estratificación entrecruzada (Hongn y Seggiaro, 2001). En la zona de Pucarilla y Pucará, las ignimbritas presentes son vitrofíricas rojizas y se relacionan con las de la caldera del Galán. En Pucarilla se disponen en mantos extensos y de poco espesor, típico de facies distales al centro de emisión. La unidad basal de la ignimbrita está poco soldada, con escaso contenido de pómez blancas y de fragmentos líticos del basamento, mientras que la parte superior es una ignimbrita soldada caracterizada por un abundante contenido de fiammes (Hongn y Seggiaro 2001: 31).

En las depresiones de los valles, se hallan depósitos cuaternarios terrazados constituidos por sedimentos gruesos (gravas y arenas) con intercalaciones delgadas de limos y arcillas, y ocasionales niveles de cenizas volcánicas (Hongn y Seggiaro 2001). Los cursos fluviales que desembocan en las depresiones dan lugar a abanicos aluviales (gravas, arenas y arcillas barreales) muy bien definidos (Hongn y Seggiaro 2001).

\section{Acercamiento teórico/metodológico}

Desde lo teórico, nos centramos en la teoría de la práctica y partimos de la premisa que sugiere que las elecciones tecnológicas son socialmente construidas, aprendidas y transmitidas (Dobres y Robb 2005). Desde estas líneas sostenemos que las cuestiones tecnológicas involucran múltiples dimensiones que dan lugar a las estructuras sociales, su reproducción e interacción. A partir de ello, nos planteamos la idea de que las prácticas alfareras -entendidas como una más de las prácticas socialesconstituyeron un recurso para la interacción jugando un papel importante en la reproducción social de las poblaciones locales del sector bajo estudio. Entendemos a las elecciones técnicas alfareras como resultado de un proceso de acciones observadas y transmitidas, resultado de una forma de hacer y pensar particular de un grupo social (Roux 2011).
La muestra total de Tacuil y Gualfín asciende a 2133 fragmentos. Para el Fuerte Tacuil y la División Arquitectónica A de los recintos bajos trabajamos con 1219 fragmentos, de los cuales 384 fueron recuperados en el Fuerte y 835 en la DAA de los recintos bajos. Se definieron 9 grupos de pastas y dos variedades a partir del uso de lupa binocular (marca M51000) y lupa digital (BW-40X) y teniendo en cuenta características como textura, presencia y densidad de antiplásticos, distribución, abundancia, forma y tamaño. La separación se realizó siguiendo atributos como el acabado de superficie lo que, en algunos casos, dio lugar a la conformación de grupos y variedades. Para ello se siguieron criterios planteados por Cremonte (2001), completando fichas diagramadas para tal fin. Una segunda etapa de trabajo consistió en la caracterización petrográfica de un conjunto definido a partir de la primera caracterización submacroscópica de pastas. Del total de la muestra se seleccionó una submuestra de 26 fragmentos para cortes delgados. Para la selección de los mismos se buscó obtener una muestra de cada grupo y, en lo posible, considerar diferentes estilos cerámicos. Los cortes fueron realizados en el Laboratorio de Petrotomía de la Facultad de Ciencias Naturales (UNSa) y analizados en el laboratorio de Microscopía de la Escuela de Geología (Facultad de Ciencias Naturales-UNSa), utilizando microscopio de polarización Olympus BX51. Se completó el registro con fotomicrografías de los cortes.

Para el caso de Gualfín se trabajó con 914 fragmentos, de los cuales 419 provienen del Fuerte y 495 de los recintos bajos asociados al mismo. A partir del uso de lupa binocular pudimos diferenciar 8 grupos de pastas y 2 variedades; de los cuales se eligió una muestra de 9 fragmentos para realizar observaciones petrográficas.

Para la identificación mineralógica seguimos a Kerr (1965). Entre los criterios de trabajo tuvimos en cuenta: Naturaleza mineralógica de la muestra, tamaño de minerales ${ }^{3}$, grado de esfericidad y redondez fue estimado teniendo en cuenta la propuesta de Orton et al. (1997: 268). La identificación de los minerales, su frecuencia y relación con respecto a la pasta como así también a las cavidades se realizó mediante point counter, tomando un promedio de 250 mediciones -a distancias constantespor corte delgado. Los fondos de pastas fueron descriptos según la clasificación propuesta por Cremonte y Pereyra Domingorena (2013), en pseudolepidoblástica, microgranosa y criptofilitosa o fluidal.

\section{Características generales del conjunto cerámico}

El conjunto del pukara de Tacuil pudo dividirse en decorados, no decorados y pulidos/bruñidos

\footnotetext{
3 Según la escala de Wentworth: limo grueso $(0,031-0,062$ $\mathrm{mm})$, arena muy fina $(0,062-0,125 \mathrm{~mm})$, arena fina $(0,125-$ $0,25 \mathrm{~mm})$, arena mediana $(0,25-0,5 \mathrm{~mm})$, arena gruesa $(0,5-1$ $\mathrm{mm})$, arena muy gruesa (1-2 $\mathrm{mm}$ ).
} 
monocromos 4 . Aquí, el 31\% ( $\mathrm{N}=119)$ corresponden a fragmentos decorados pintados asignados a los estilos Santa María (en adelante SM) en sus variedades bicolor negro sobre crema, tricolor; Belén y otros considerados como indeterminados. Un grupo importante constituye el de los pulidos y bruñidos monocromos $22 \%$ ( $\mathrm{N}=84$ ), los cuales presentan un acabado, en general, de tipo fino, denominados Churcal rojo pulido por Raffino (1984) ${ }^{5}$. Aquí encontramos fragmentos de superficies bruñidas (rojizas, marrones y negras/grises) y otros pulidos de superficie gris incisa (asociados al Temprano en la zona); además de cuatro fragmentos de piezas abiertas de la variedad negro pulido del Tardío (sensu Baldini y Sprovieri 2009) ${ }^{6}$. Los materiales de manufactura tosca (o no decorados) comprenden el $47 \%(\mathrm{~N}=181)$ de la muestra siendo principalmente fragmentos de piezas cerradas. Aquí identificamos toscos alisados y aquellos que presentan las superficies peinadas. Los primeros comprenden 126 y los segundos 55. En general se observa un alto grado de fragmentación en la mayoría de los casos.

Para la DAA contamos con 835 fragmentos, de los cuales 237 fueron recuperados en superficie y 598 de sondeos planteados en los recintos 6 y 15 de dicha división?. Entre los decorados, se identificaron los estilos SM, la variedad negra pulida del Tardío (sensu Baldini y Sprovieri 2009), escasos pulidos grises tempranos y tres pequeños fragmentos de posible filiación inca. Entre la cerámica SM decorada se encuentran fragmentos de la subtradición Calchaquí (sensu Calderari 1991) ${ }^{8}$ y fragmentos con decoración externa en negro sobre crema e interior pintura roja ${ }^{9}$. Se han diferenciado también fragmentos

4 Grupo que fue considerado por separado debido a las características de manufactura, algunos ejemplares con pulido de acabado fino, monocromos (rojizos, negros y grises), con pastas medianas y finas.

5 Fragmentos pulidos con similares características de manufactura fueron recuperados por Raffino y Cigliano en los sitios El Churcal, La Arcadia, Cerro El Dique, Humanao durante los '70 y se encuentran en las colecciones del depósito 25 del Museo de La Plata.

6 Piezas de esta variedad también fueron halladas en un contexto funerario Tardío-Inca en Payogastilla, al sur del Valle Calchaquí (Vasvari 2014).

7 Entre los materiales de recolección de superficie 30 corresponden a refractarios empleados en la producción metalúrgica, de los cuales 22 son de cerámica y 8 líticos.

${ }^{8}$ Calderari distingue entre la Agrupación estilística Calchaquí y la Cachi. La primera presenta notable similitud a nivel morfológico y decorativo con la tradición SM del valle de Yocavil, mientras que la subtradición Cachi se diferencia en cuanto a forma, patrones decorativos geométricos y un repertorio mucho más simple que el Calchaquí (Calderari 1991: 6).

${ }^{9}$ Para sitios de la Quebrada del Toro se menciona el hallazgo de fragmentos SM con interior rojo pulido, al que se denomina como una subtradición estilística SM Rojo Pulido Interno (Cigliano y Calandra 1973, citado en Calderari 1991: 7). de estilo Belén negro sobre rojo pulido o Belén inca, cuya presencia ha sido mencionada en los pukaras de Gualfín y Tacuil por Cigliano y Raffino (1975), Raviña y colaboradores (1983). Entre los materiales no decorados (60) se diferencian los grupos peinados, superficies alisadas de manera irregular y alisados uniformes. Estos dos últimos se distinguen por su tratamiento de superficie, pasta y espesor de paredes.

Un conjunto particular en Tacuil recintos bajos es el de cerámica refractaria (moldes, crisoles e intermediarios), asociado a la producción de objetos de metal, algunos de los cuales presentan residuos metálicos adheridos a sus paredes y una sustancia blanquecina en una de sus superficies. Los análisis morfológicos y de caracterización composicional permitieron reconocer operaciones del proceso de producción metalúrgica asociadas a la fundición de minerales de cobre o cobre metálico y el empleo de aleación de bronce estañifero.

Para el Fuerte Gualfín se recuperaron 419 fragmentos de los cuales el $54 \%(\mathrm{~N}=225)$ se pueden asociar al grupo de los no decorados, 188 decorados y 6 pulidos. Entre los materiales decorados predomina el estilo SM en sus variedades bicolor en negro sobre crema, negro sobre rojo y tricolor. El conjunto negro sobre crema es mayoritario, y contiene una variante cuya superficie interna está pintada de roja. La misma también fue mencionada en otros sitios del Calchaquí como los recintos bajos de Tacuil y en El Churcal (Raffino 1984) y en el sitio La Paya (Calderari 1992). Además, contamos con fragmentos de la variedad Valle Arriba (sensu Serrano 1976 [1958]), en los cuales se aprecian representaciones de la serpiente y ave bicéfala, que Serrano (1976 [1958]) propusiera como una particularidad de esta subtradición. También registramos siete fragmentos de estilo Belén negro sobre rojo pulido; que fueran mencionados para el Fuerte y recintos bajos de Tacuil. Entre los no decorados se encuentran fragmentos de piezas de superficies de manufactura tosca, alisadas y peinadas. El grupo de los pulidos comprende material monocromo de color negro y un fragmento de superficie externa naranja e interna roja pulida (indeterminado).

La muestra de los recintos bajos de Gualfín cuenta con 495 fragmentos, donde la mayor cantidad se agrupa en la categoría no decorados ( $\mathrm{N}=298), 186$ corresponden al grupo de los decorados y sólo 11 pulidos. Entre los decorados registramos material pintado, asociado al estilo SM (negro sobre crema y negro sobre rojo, negro sobre crema e interior pintura roja) y fragmentos asignados al estilo Belén pulido. Además de fragmentos pulidos grises y negros monocromos. Éstos últimos presentan características de manufactura similar a los negros pulidos del Tardío (sensu Baldini y Sprovieri 2009), variedad que también fuera hallada en sitios de Tacuil. Para el Fuerte de Gualfín, el material negro pulido hallado por Raviña et.al (1983) corresponde al estilo Famabalasto negro grabado. 


\section{Características de las pastas a nivel submacroscópico y microscópico}

Mediante el uso de lupa binocular y digital, para Tacuil se diferenciaron nueve grupos y dos variedades, los cuales son referidos en el Tabla 1.

De esta clasificación inicial se realizaron 26 cortes delgados para su análisis petrográfico. Del total, diez muestras provienen del Fuerte de Tacuil y 16 de la DAA recintos bajos. Se buscó -en lo posible- que fueran representativos de cada grupo, de las diferentes morfologías presentes en la muestra general (abiertas y cerradas) y de los tratamientos de superficie observados, para cruzar datos con los contextos de hallazgo.

Las caracterizaciones petrográficas del conjunto analizado permitieron separar cuatro tipos de pastas: gruesas, medianas, finas y muy finas (Tabla 2). Los porcentajes de inclusiones minerales, matriz y cavidades identificadas para el conjunto de Tacuil, fueron volcadas en la tabla 3.

Para el caso de Gualfín, se diferenciaron ocho grupos de pastas y dos variedades a partir del uso de lupa binocular (Tabla 4).

De esta primera clasificación se seleccionó una muestra de 9 fragmentos para realizar caracterizaciones petrográficas. Las caracterizaciones petrográficas permitieron diferenciar tres tipos de pastas (Tabla 5). Los datos cuantificados se presentan en la tabla 6 .

\section{Síntesis y discusiones sobre la petrografía de las muestras de Tacuil y Gualfín}

Los análisis sobre una muestra de 35 fragmentos de cerámica recuperada en los asentamientos de Fuerte y recintos Bajos de Tacuil y Gualfín han permitido obtener una primera caracterización de pastas cerámicas a través del estudio petrográfico.

Para Tacuil hemos diferenciado cuatro tipos de pastas. En el caso de las gruesas, que contienen entre un 30 y $43 \%$ de inclusiones de tamaño arena mediana a muy gruesa, encontramos fragmentos de cerámicas toscas peinadas, dos fragmentos de moldes para la producción metalúrgica y alfarería de estilo SM tricolor y bicolor. Las pastas intermedias, con un porcentaje entre el 19 y $29 \%$ de inclusiones de tamaño arena fina y gruesa, presentan una gran variedad, morfologías de piezas y estilos decorativos. Encontramos aquí fragmentos asociados al grupo de los pulidos/bruñidos monocromos, SM tricolor (con modelados aplicados al pastillaje), bicolor negro sobre crema e interior rojo pintado. Para el conjunto de estilo SM se diferenciaron dos modalidades de pastas. Por un lado, aquellas laminares con abundante cantidad de muscovita de tamaño arena media a gruesa y menor proporción de otros minerales $y$, por otro lado, pastas con menor cantidad de muscovitas de tamaño arena fina a muy fina y mayor cantidad de clastos y/o litoclastos. Una constante en las muestras SM es la presencia de tiesto molido en diferentes proporciones, siendo menor en aquellos de pasta laminar. Las pastas finas, con un porcentaje entre el 9 y $19 \%$ de inclusiones tamaño arena muy fina y mediana, se asocian a fragmentos asignados al estilo SM en sus variedades bicolor en negro sobre crema, tricolor y la subtradición Valle Arriba, Belén negro sobre rojo pulido, alisado uniforme indeterminado y negro pulido del Tardío. En el caso de los fragmentos SM observamos pastas con inclusiones muy finas y finas para las variedades negro sobre crema, y tricolor; como también en los dos de la subtradición Valle Arriba. En todos los fragmentos de este estilo detectamos la presencia de tiesto molido, en diferentes proporciones; no así en los Belén. Además, hallamos agregados de tiesto molido en los alisados y en la muestra de alfarería negra pulida del Tardío de este grupo. Finalmente, las pastas muy finas contienen menos del $10 \%$ de inclusiones como feldespatos, tiesto molido, plagioclasas, cuarzo y escasa pómez, junto con abundantes cavidades o poros. Corresponden a la variedad negra pulida del Tardío y al estilo Belén. Muchos de los minerales visibles en estas pastas corresponden a muscovitas, biotitas y cuarzos, tamaño arena muy fina que, consideramos, se hallan formando parte de la materia prima natural.

Para Gualfín, diferenciamos pastas gruesas, intermedias y finas. Las primeras presentan una proporción de inclusiones o antiplásticos mayores al 37\%, con tamaños que oscilan entre arena media y gruesa; correspondiendo a fragmentos de piezas cerradas de estilo SM (en las variedades tricolor y negro sobre crema). En este grupo encontramos un tipo de pastas de textura laminar, con abundante cantidad de muscovitas de tamaño arena mediana a gruesa, similares al descripto para Tacuil; observándose escasas o nulas inclusiones de tiesto molido. Las pastas intermedias presentan entre un $23 \mathrm{y}$ un $27 \%$ de inclusiones de tamaños diversos (entre arena fina a gruesa) y con la presencia de tiesto molido en cantidad importante. Estas pastas han sido observadas en fragmentos de estilo SM negro sobre crema y negro sobre rojo. El tipo de pasta fino contiene menos del $22 \%$ de inclusiones de tamaño arena fina y mediana, y ha sido caracterizada para fragmentos de estilo SM tricolor, Belén inca, variedad negro pulido del Tardío y un fragmento gris bruñido.

Con respecto a la relación entre matriz y agregados, para Tacuil se observa una recurrencia en el tipo de minerales como muscovita, feldespatos, plagioclasas, cuarzo, biotita y, en menor cantidad, también minerales opacos, fragmentos líticos de origen granítico, metamórfico y volcánico (Tabla 3). El porcentaje de inclusiones con respecto a la matriz es en general menor al 30\%, aunque en algunas muestras se pudo observar mayor cantidad de inclusiones. Para Gualfín destacamos la recurrencia de minerales como cuarzo, feldespatos, feldespatos 
alterados y plagioclasas, además de fragmentos de líticos de origen granítico. Las muscovitas han sido reconocidas para el grupo de pastas gruesas y textura laminar.

Se reconoció una litología relativamente uniforme en las pastas de la muestra cerámica y similar a la litología local en ambas localidades (Tacuil y Gualfín). Para Tacuil destacamos dos materias primas principales que presentan características composicionales diferentes. Por un lado, pastas con abundante muscovita de tamaño mediano y, por otro lado, pastas con mayor proporción de inclusiones minerales y litoclastos. De estas dos materias primas generales se desprenderán variedades diferenciables por las características de inclusiones, variedad y frecuencia. Para el primer caso, la presencia de muscovita en las arcillas es común en la zona, tal mineral podría provenir de la alteración y erosión de las rocas metamorficas (esquistos, gneises sillimaníticos, metacuarcitas y filitas) correspondientes al Complejo Metamórfico Rio Blanco y la Formación La Paya (Hongn y Seggiaro 2001). Para el segundo caso, rocas de naturaleza plutónica como granodioritas, monzogranitos, granitos y pegmatitas constituyen los extensos afloramientos cambro-ordovícicos que conforman el Complejo Eruptivo Oire y los granitos Angostura y Pucará, cercanos a Tacuil (Hongn y Seggiaro 2001). La alteración, meteorización y erosión de los granitos del complejo Oire puede generar arenas con importante contenido de cuarzo, feldespatos, plagioclasas y muscovitas.

Un pequeño grupo de pastas contienen litoclastos metamórficos, además de feldespatos alterados y cuarzo de origen metamórfico. Las mismas corresponden a fragmentos de refractarios (moldes), recolectados en la DAA de los recintos bajos, y un monocromo pulido de los hallados en el Fuerte de Tacuil. Estos tipos de agregados son propios de ambientes de grado medio de metamorfismo. En cercanías de la zona de Tacuil encontramos rocas metamórficas del complejo Río Blanco (Hongn y Seggiaro 2001: 71). Litoclastos de origen sedimentario han sido observados en dos cortes de la variedad SM Valle Arriba ${ }^{10}$. Clastos de arenisca, pelitas y líticos de origen sedimentario no son comunes en la zona a pesar de que es posible encontrar areniscas de la Formación Quebrada de los Colorados en las áreas de Colomé y Tacuil (Hongn y Seggiaro 2001: 36). Por otro lado, en dos casos hallamos litoclastos de origen volcánico, los cuales pudieron provenir de depósitos de flujos, cuyas fuentes principales serían las ignimbritas, aportando cenizas, pómez, cristales y líticos (Páez y Arnosio 2009: 15). Debemos recordar que el sitio de Tacuil (Fuerte y recintos bajos) se hallan asociados directamente a depósitos de ignimbrita (Hongn y Seggiaro 2001).

Para Gualfín, el porcentaje de inclusiones de las muestras analizadas no supera el $22 \%$, a excepción de tres de ellas que presentan el $24 \%$ y $37 \%$. Los minerales observados en las muestras se encuentran disponibles en cercanías de Gualfín, aflorando como parte del complejo eruptivo Oire, distinguiéndose en particular la fase que presenta granitos y granodioritas de grano grueso con megacristales gneizados y con intensa pegmatización

\footnotetext{
${ }^{10}$ La variedad o subtradición Valle Arriba ha sido considerada como propia del sector Sur del valle Calchaquí (Serrano 1976 [1958]). Para las quebradas altas, se han registrado fragmentos en sitios como Tacuil, Gualfín, Pucarilla (Ambrosetti 1899) y Pueblo Viejo (Arechaga 2011).
}

Tabla 1. Grupos de pastas definidos para Tacuil a partir de atributos submacroscópicos.

Table 1. Pasta groups defined for Tacuil from submacroscopic attributes.

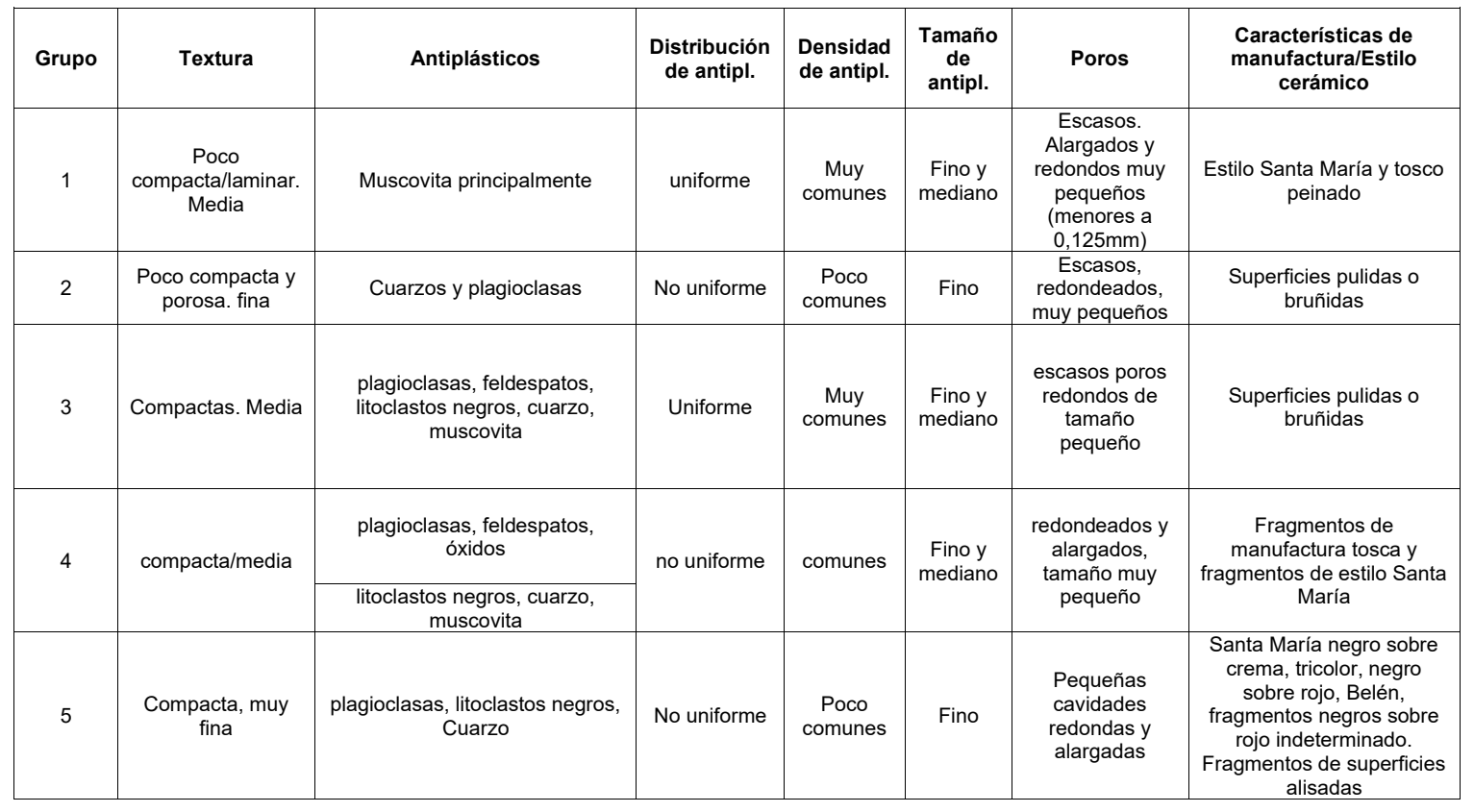


Tabla 2. Tipos de pastas definidos para Tacuil a partir de observaciones microscópicas realizadas en cortes delgados.

Table 2. Types of pasta defined for Tacuil from microscopic observations made in thin cuts.

\begin{tabular}{|c|c|c|c|c|c|}
\hline $\begin{array}{l}\text { Tipo de } \\
\text { pasta. } \\
\text { Tacuil }\end{array}$ & $\begin{array}{c}\text { Porcentaje } \\
\text { de } \\
\text { inclusiones }\end{array}$ & $\begin{array}{c}\text { Tamaño } \\
\text { de } \\
\text { inclusiones }\end{array}$ & Fondo de pasta & $\begin{array}{c}\text { Tipo de } \\
\text { inclusiones }\end{array}$ & $\begin{array}{r}\mathrm{N}^{\circ} \\
\text { corte }\end{array}$ \\
\hline \multirow{5}{*}{ Gruesa } & \multirow{5}{*}{$\begin{array}{l}\text { Entre } 30 \mathrm{y} \\
43 \%\end{array}$} & \multirow{5}{*}{$\begin{array}{c}\text { Arena } \\
\text { mediana a } \\
\text { muy gruesa }\end{array}$} & Microgranosa & $\begin{array}{c}\text { A: } \\
\text { presencia de } \\
\text { muscovita, } \\
\text { feldespatos, } \\
\text { plagioclasas, } \\
\text { tiesto y } \\
\text { litoclastos de } \\
\text { roca granítica }\end{array}$ & 3 \\
\hline & & & \multirow[b]{2}{*}{ seudolepidoblástica } & $\begin{array}{c}\text { B: } \\
\text { muscovita, } \\
\text { feldespatos, } \\
\text { escaso tiesto. }\end{array}$ & 7 \\
\hline & & & & $\begin{array}{c}\mathrm{E}: \\
\text { plagioclasa, } \\
\text { muscovita, } \\
\text { feldespato, } \\
\text { lítico } \\
\text { granítico, } \\
\text { cuarzo }\end{array}$ & 4 \\
\hline & & & \multirow[b]{2}{*}{$\begin{array}{l}\text { Criptofilitosa y } \\
\text { microgranosa }\end{array}$} & $\begin{array}{c}\text { C: cuarzo, } \\
\text { feldespatos, } \\
\text { plagioclasas, } \\
\text { cuarzos de } \\
\text { origen } \\
\text { metamórfico } \\
y \\
\text { sedimentario, } \\
\text { muscovitas }\end{array}$ & 23 \\
\hline & & & & $\begin{array}{c}\text { D: cuarzo, } \\
\text { feldespatos, } \\
\text { plagioclasas, } \\
\text { cuarzos de } \\
\text { origen } \\
\text { metamórfico } \\
y \\
\text { sedimentario, } \\
\text { muscovitas, } \\
\text { pómez }\end{array}$ & 24 \\
\hline \multirow{4}{*}{ Intermedia } & \multirow{4}{*}{19 y $29 \%$} & \multirow{3}{*}{$\begin{array}{l}\text { Arena } \\
\text { fina }\end{array}$} & \multirow[t]{2}{*}{ Microgranosa } & $\begin{array}{c}\text { A: } \\
\text { feldespatos, } \\
\text { plagioclasa, } \\
\text { muscovita, } \\
\text { biotita, pómez }\end{array}$ & 13 \\
\hline & & & & $\begin{array}{r}\text { B: cuarzo, } \\
\text { feldespatos, } \\
\text { plagioclasa, } \\
\text { tiesto molido }\end{array}$ & 5 \\
\hline & & & Criptofilitosa & $\begin{array}{c}\text { A: tiesto, } \\
\text { muscovita, } \\
\text { cuarzo, } \\
\text { plagioclasa }\end{array}$ & 8 \\
\hline & & $\begin{array}{r}\text { Arena } \\
\text { mediana }\end{array}$ & Criptofilitosa & $\begin{array}{c}\text { A: } \\
\text { feldespatos } \\
\text { alterados, } \\
\text { plagioclasas } \\
\text { alteradas, } \\
\text { muscovita, }\end{array}$ & 2 \\
\hline
\end{tabular}

Falda Ciénaga, que se hallan en sectores más alejados como en la puna (Hongn y Seggiaro 2001).

Al igual que en Tacuil, las muestras de material SM de Gualfín presentaban dos tipos de pastas; una de tipo laminar con abundante muscovita de tamaño arena mediana y otra con mayor cantidad de inclusiones minerales y muscovitas de menor tamaño. A diferencia de Tacuil, donde las pastas laminares se asociaban principalmente a fragmentos negro sobre crema, en Gualfín se observó este tipo de pasta en un tiesto SM tricolor.

El agregado de tiesto molido se ha observado en 17 cortes de Tacuil y en 7 de Gualfín. En general, presentan bordes angulosos a subangulosos con una presencia mayor al 10\%, mientras que dos cortes tienen entre el 20 y $22 \%$ de este agregado, para Tacuil, y en porcentajes que oscilan entre el 5 y $7 \%$ y mayores al $11 \%$, para Gualfín. En general, las inclusiones son de tamaño fino a mediano (en fragmentos SM tricolor, bicolor negro sobre crema y alfarería negra pulida del Tardío) y tamaño arena fina en los ejemplares del estilo SM variedad Valle Arriba. En muestras del estilo SM con pasta mediana y abundante cantidad de muscovita, se detectó la presencia de tiesto de tamaño arena mediana. Mientras que los tiestos molidos gruesos y muy gruesos fueron reconocidos en un fragmento pulido monocromo (Tacuil). No se ha detectado tiesto molido en muestras de estilos tosco peinado, alisado uniforme, SM negro sobre crema e interior pintura roja, Belén ${ }^{11}$ y pulido monocromo.

11 En pastas de cerámica Belén del valle del Bolsón y Antofagasta de la Sierra no se ha detectado tiesto molido (Pérez 2013; Puente 2012b).

(Hongn y Seggiaro 2001: 13). Este afloramiento presenta granitos y granodioritas con fenocristales de feldespato potásico, rocas biotíticas y moscovíticas, grises y rosadas; también con abundantes pegmatitas. Inclusiones de origen sedimentario como pelitas, grauwaca y arcilitas han sido detectadas en dos muestras. Este tipo de minerales se pueden hallar en la Formación Puncoviscana, la cual está caracterizada por una alternancia de pelitas, grauwacas y areniscas. Los depósitos de esta formación más cercanos se encuentran en al sur de la actual localidad de Molinos y en Humanao, en la zona de Seclantás Adentro y El Churcal, hacia el sur de Angastaco, en la localidad de San Lucas; y en depósitos de la Formación bajos de la DAA de Tacuil.

A nivel regional, el agregado de tiesto molido ha sido registrado en pastas de piezas del Tardío de distintos sectores del actual NOA, entre ellos materiales SM bicolor y tricolor de Rincón Chico, valle de Yocavil (Palamarczuk 2002), SM del Valle de Tafí (Páez 2010), entre otros. Acordamos con Puente (2012a) en que esta práctica va más allá de lo meramente funcional. La incorporación de tiesto en gran parte de las muestras analizadas nos permite plantear la idea de una elección vinculada al
Tampoco hemos observado este tipo de agregados en los fragmentos de moldes que recuperamos en los recintos 


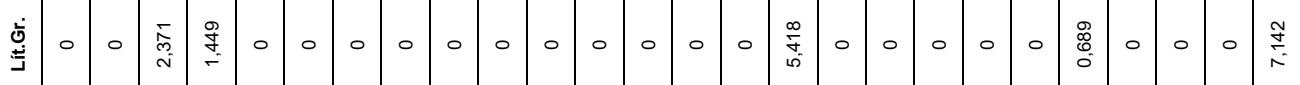

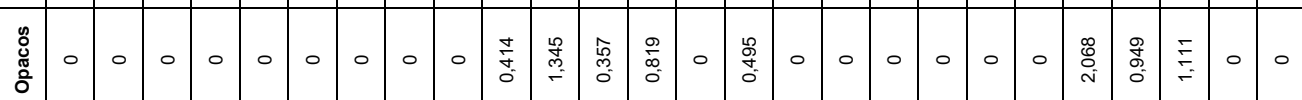

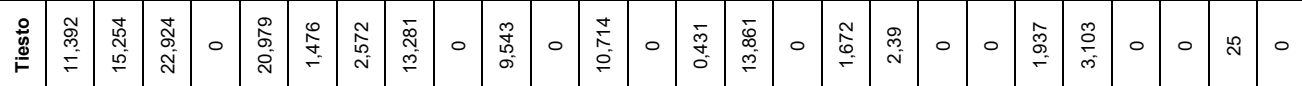

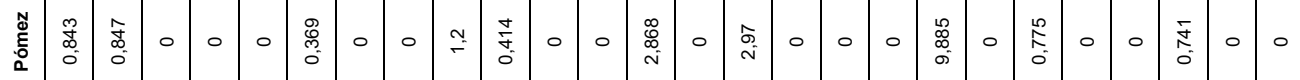

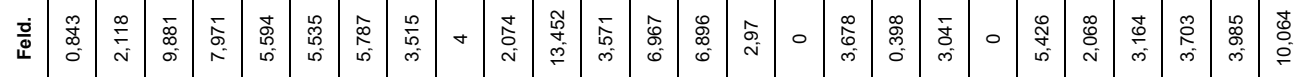

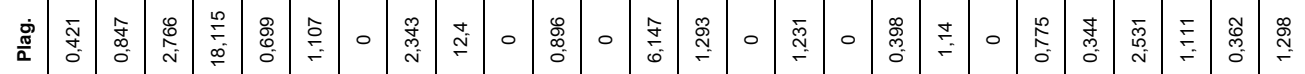

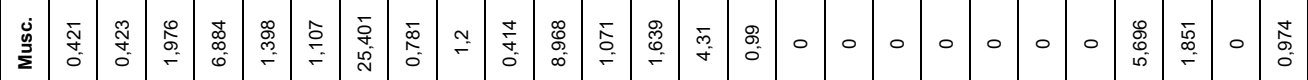

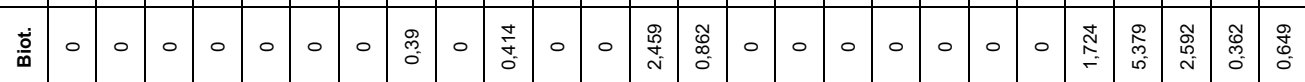

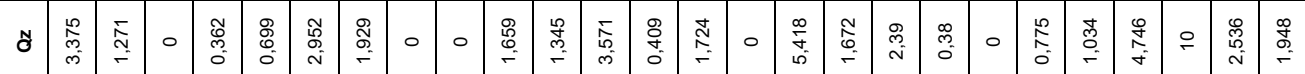

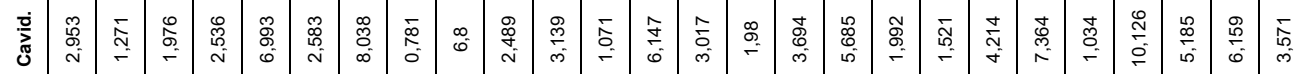

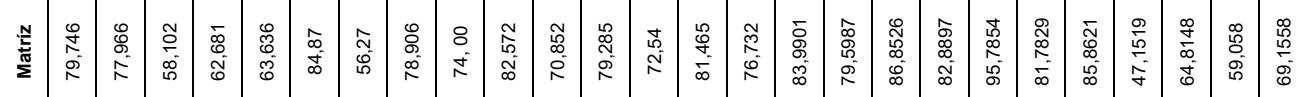

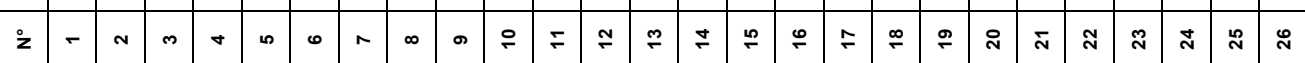


Tabla 4. Grupos de pastas definidos para Gualfín a partir de atributos submacroscópicos.

Table 4. Groups of pasta defined for Gualfín based on submacroscopic attributes.

\begin{tabular}{|c|c|c|c|c|c|c|c|}
\hline Grupo & Textura & Antiplásticos & $\begin{array}{l}\text { Distribución } \\
\text { de antipl. }\end{array}$ & $\begin{array}{l}\text { Densidad } \\
\text { de antipl. }\end{array}$ & $\begin{array}{l}\text { Tamaño } \\
\text { de antipl. }\end{array}$ & Poros & $\begin{array}{c}\text { Características de } \\
\text { manufactura/Estilo cerámico }\end{array}$ \\
\hline 1 & $\begin{array}{l}\text { Compacta/laminar, } \\
\text { media a gruesa }\end{array}$ & $\begin{array}{l}\text { Principalmente } \\
\text { muscovita }\end{array}$ & Uniforme & $\begin{array}{l}\text { Muy } \\
\text { comunes }\end{array}$ & $\begin{array}{l}\text { Mediano, } \\
\text { grueso }\end{array}$ & Escasos & $\begin{array}{c}\text { Santa María negro sobre crema } \\
\text { y negros sobre crema interior } \\
\text { rojo }\end{array}$ \\
\hline 2 & $\begin{array}{l}\text { Poco compacta/ } \\
\text { desgranable }\end{array}$ & $\begin{array}{l}\text { Cuarzo, feldespato, } \\
\text { litoclastos negros, } \\
\text { muscovita fina }\end{array}$ & Uniforme & $\begin{array}{c}\text { Muy } \\
\text { comunes }\end{array}$ & $\begin{array}{l}\text { Mediano y } \\
\text { fino }\end{array}$ & $\begin{array}{l}\text { Escasos, } \\
\text { redondeados }\end{array}$ & $\begin{array}{l}\text { Manufactura tosca, superficies } \\
\text { alisadas y peinadas }\end{array}$ \\
\hline 3 & compacta y media & Cuarzo, feldespato & Uniforme & Comunes & $\begin{array}{l}\text { Mediano y } \\
\text { fino }\end{array}$ & $\begin{array}{l}\text { Escasos, } \\
\text { redondeados }\end{array}$ & $\begin{array}{l}\text { Santa María negro sobre rojo y } \\
\text { negro sobre crema, toscos } \\
\text { alisados y peinados }\end{array}$ \\
\hline $\begin{array}{c}3 \\
\text { variedad } \\
\text { A }\end{array}$ & compacta y media & $\begin{array}{l}\text { Cuarzo, feldespato. } \\
\text { Tiesto molido }\end{array}$ & Uniforme & Comunes & $\begin{array}{l}\text { Mediano y } \\
\text { fino }\end{array}$ & $\begin{array}{l}\text { Escasos, } \\
\text { redondeados }\end{array}$ & Santa María \\
\hline 4 & Compacta y fina & $\begin{array}{l}\text { Cuarzo, feldespatos } \\
\text { y muscovita fina }\end{array}$ & No uniforme & Comunes & Finos & $\begin{array}{l}\text { Escasos, } \\
\text { redondeados }\end{array}$ & $\begin{array}{c}\text { cerámica Santamariana negro } \\
\text { sobre crema, variedad Valle } \\
\text { Arriba y tricolor }\end{array}$ \\
\hline
\end{tabular}

reciclado de fragmentos que puede estar fundamentada por decisiones funcionales o no (Puente 2012a).

La presencia de pómez se observó en diez de las 26 muestras analizadas de Tacuil, aunque con proporciones diferentes ya que en seis muestras son menores al 1\%; en cuatro comprenden entre el 1 y el $3 \%$ y en un caso mayor al 9\%. Las inclusiones presentan una forma redondeada o subredondeada, con tamaños de tipo arena fina a muy fina. El primer grupo (cantidad menor al $1 \%$ ) está compuesto por fragmentos de estilo SM bicolor negro sobre crema, SM variedad tricolor, un monocromo pulido/bruñido, negro pulido del Tardío y un fragmento refractario de molde. En este caso el vidrio presenta tamaño arena fina. Uno de los tres fragmentos de estilo Belén presentaba un porcentaje de pómez mayor al $9 \%$. En este caso, los tamaños de estas inclusiones pumíceas varían entre arena fina a arena muy gruesa, hallándose también abundante cantidad de tamaño limo grueso. De este tamaño también observamos anfíboles, como parte de la matriz. Para Gualfín, se han reconocido inclusiones pumíceas de bordes redondeados y tamaño arena fina, en un fragmento Belén.

Inclusiones de vidrio volcánico han sido registradas en materiales tardíos del valle de Hualfín, Catamarca. Aquí, Zagorodny et al. (2010) observan una clara tendencia volcano-piroclástica en las pastas de fragmentos Belén, lo cual consideran como una incorporación de tipo intencional. Por su parte, lucci (2013) encuentra, en muestras de del Valle de Hualfín ${ }^{12}$, que el tiesto molido y fragmentos pumíceos son recurrentes, mencionando que este último componente puede hallarse de manera natural en las arenas incorporadas a las pastas o también que fueran incluidos en las arcillas de manera intencional ${ }^{13}$. Para el valle del Bolsón, Catamarca, Puente (2012b) observa una homogeneidad en las materias primas de piezas Belén; mencionando la presencia de inclusiones no plásticas de vidrio vesicular acompañado de cuarzo, clastos minerales y líticos ${ }^{14}$. También se ha detectado este agregado en materiales Belén y en algunos fragmentos SM de los sitios Alumbrera y Bajo del Coypar II, en Antofagasta de la Sierra (Pérez 2013) ${ }^{15}$. Por su parte,

\footnotetext{
12 Sitios Cerro Colorado, El Molino, Loma de los Antiguos, Pueblo Viejo de El Eje, Loma de la Escuela y Loma de Ichanga (lucci 2013).

${ }^{13}$ Para el caso de la cerámica ordinaria, señala que el agregado de tiesto molido es característico de este tipo de piezas. Con respecto a la presencia de pómez tanto en piezas ordinarias como en las Belén, distingue entre aquellas con gran cantidad, y tamaño mediano/grande y otras cuya presencia es constante y en porcentajes más bajos. Interpreta a las primeras como un agregado intencional y a las segundas como un agregado incorporado como parte de las arenas o añadidos de depósitos con estos materiales (lucci 2013: 402).

14 Sitios La Angostura, los Viscos y El Duraznito (Puente 2012b). Análisis petrográficos junto con estudios de Activación neutrónica, permitieron a la autora postular una producción de tipo local y de carácter doméstico (Puente 2012b: 87 y 88). 15 En Bajo del Coypar II los fragmentos Belén presentan
} 
Tabla 5. Tipos de pastas definidos para Gualfín a partir de observaciones microscópicas realizadas en cortes delgados.

Table 5. Types of pastes defined for Gualfín from microscopic observations made in thin cuts.

\begin{tabular}{|c|c|c|c|c|c|}
\hline $\begin{array}{l}\text { Tipo de pasta. } \\
\text { Gualfín }\end{array}$ & $\begin{array}{l}\text { Porcentaje de } \\
\text { inclusiones }\end{array}$ & $\begin{array}{l}\text { Tamaño de } \\
\text { inclusiones }\end{array}$ & $\begin{array}{l}\text { Fondo o estructura de } \\
\text { pasta }\end{array}$ & Tipo de inclusiones & $\begin{array}{l}N^{\circ} \text { de } \\
\text { corte }\end{array}$ \\
\hline \multirow{3}{*}{ Gruesa } & \multirow{3}{*}{ Mayores al $37 \%$} & \multirow{3}{*}{$\begin{array}{l}\text { Arena mediana } \\
\text { a muy gruesa }\end{array}$} & Seudolepidoblástica & $\begin{array}{c}\text { A: Inclusiones de muscovita, tiesto (escaso, pero de tamaño arena } \\
\text { grande), nódulos de arcilla, cuarzo, feldespatos, feldespatos } \\
\text { alterados, feldespatos alterados a sericita }\end{array}$ & 33 \\
\hline & & & \multirow[t]{2}{*}{ Microgranosa } & $\begin{array}{l}\text { A: inclusiones de cuarzo, lítico granítico, feldespatos, cuarzo } \\
\text { policristalino, feldespatos alterados a sericita, feldespatos } \\
\text { alterados a sericita con presencia de hierro, feldespatos alterados, } \\
\text { minerales opacos, muscovita (de tamaño arena fina), biotita, }\end{array}$ & 34 \\
\hline & & & & plagioclasa & \\
\hline \multirow[t]{2}{*}{ Intermedia } & \multirow[t]{2}{*}{23 y un $27 \%$} & Arena mediana & Microgranosa & $\begin{array}{l}\text { A: Tiesto molido, cuarzo, lítico granítico, feldespatos, feldespatos } \\
\text { alterados, feldespatos alterados a sericita, plagioclasa, muscovita, } \\
\text { biotita }\end{array}$ & 27 \\
\hline & & $\begin{array}{l}\text { Arena fina a } \\
\text { gruesa }\end{array}$ & $\begin{array}{c}\text { Microgranosa y } \\
\text { pseudolepidoblástica }\end{array}$ & A: Tiesto, cuarzo, plagioclasa, biotita, lítico granítico, muscovita & 35 \\
\hline \multirow{5}{*}{ Fina } & \multirow{5}{*}{ Menos del $22 \%$} & Arena fina $y$ & \multirow{3}{*}{ Microgranosa } & $\begin{array}{l}\text { A: feldespatos alterados, biotita, feldespatos, cuarzos, óxidos, } \\
\text { plagioclasas, tiesto molido. }\end{array}$ & 28 \\
\hline & & mediana & & $\begin{array}{l}\text { B: cuarzo, pómez, biotitas, óxidos, plagioclasas, feldespatos, } \\
\text { opacos. }\end{array}$ & 29 \\
\hline & & & & $\begin{array}{l}\text { C: tiesto molido, feldespatos, óxidos, cuarzos, pelitas, feldespatos } \\
\text { alterados, biotitas. }\end{array}$ & 30 \\
\hline & & & $\begin{array}{l}\text { Microgranosa y } \\
\text { criptofilitosa }\end{array}$ & $\begin{array}{l}\text { A: Tiesto molido, cuarzo, feldespato, feldespatos alterados, } \\
\text { minerales opacos, biotita }\end{array}$ & 31 \\
\hline & & Arena media & Criptofilitosa & $\begin{array}{l}\text { A: Grauwaca, Pelitas, feldespatos alterados, lítico granítico, } \\
\text { cuarzo, plagioclasas, feldespatos, arcilita, sericita, óxidos. }\end{array}$ & 32 \\
\hline
\end{tabular}

Páez (2010: 775) observa la presencia de vidrio volcánico vesiculado en bajas proporciones en pasta de cerámica SM del valle de Tafí, la cual considera como parte de la arcilla utilizada en la elaboración de las piezas.

En los casos analizados, teniendo en cuenta las características texturales (redondez y tamaño) y proporciones de las inclusiones de vidrio volcánico y del entorno litológico cercano a los asentamientos, consideramos la posibilidad que la fracción de vidrio volcánico haya sido incorporado a la materia prima en las arenas $\mathrm{o}$ accidentalmente durante el proceso de preparación de la pasta. Para el caso de Tacuil, hay que recordar que el fuerte se emplaza sobre un afloramiento de ignimbrita dacítica cuyos depósitos corresponden a la ignimbrita asociada a la caldera del cerro Galán (Hongn y Seggiaro 2001) ${ }^{16}$. A manera de hipótesis, sugerimos que la presencia de inclusiones de vidrio volcánico de tamaño arena fina, en bajas proporciones, pueda ser

además pelitas, piroxenos y areniscas; mientras que para La Alumbrera, el componente principal es el vidrio volcánico. En los materiales Santamarianos de ambos sitios, es menor la cantidad de vidrio salvo en un caso de Bajo del Coypar que presenta abundante cantidad de pómez (Pérez 2013).

16 Esta ignimbrita presenta un alto contenido en cristales (plagioclasa, sanidina, cuarzo bipiramidal, biotita y óxidos), bajo en pómez y muy pocos fragmentos lávicos, constituidos en su mayoría por dacitas y andesitas. recurrente en las pastas de la cerámica de Tacuil. Esto deberá ser corroborado a partir del análisis de arenas y arcillas locales.

Integrando la información, destacamos la recurrencia de inclusiones minerales en las muestras de ambos sitios y la disponibilidad local de dichos minerales. Si cruzamos datos petrográficos y estilos cerámicos podemos señalar diferencias en la petrografía, texturas y fondos de pastas de estilos como cerámica SM, Belén, alfarería pulida o bruñida monocroma y de manufactura tosca. Para la alfarería SM observamos una variedad de pastas: gruesas, intermedias y finas, con petrografía y porosidad variable. Dentro de este estilo encontramos la subtradición Valle arriba, de pastas finas, que presenta una buena cementación de las inclusiones dentro de la matriz y escasa porosidad, lo cual permite considerar un buen trabajo de amasado para la preparación de la masa. Esta variabilidad observada en la muestra SM estudiada no se replica si tomamos en cuenta la decoración, lo cual brinda herramientas para apoyar propuestas como la de Baldini y Sprovieri sobre la menor variabilidad de motivos en la cerámica SM del valle Calchaquí medio (Baldini y Sprovieri 2014: 24).

Si tomamos en cuenta los pulidos monocromos hallados en Tacuil, diferenciamos aquellos denominados pulidos o bruñidos (o Churcal rojo pulido sensu Raffino 1984) con pastas intermedias, y la alfarería negra pulida del Tardío 


\begin{tabular}{|c|c|c|c|c|c|c|c|c|c|}
\hline 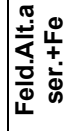 & 0 & 10 & 0 & 0 & 0 & 0 & 0 & 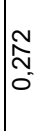 & 0 \\
\hline $\begin{array}{l}\text { 䓂 } \\
\text { 岂 }\end{array}$ & 0 & 0 & 0 & 0 & 0 & $\mid \begin{array}{l}0 \\
0 \\
0 \\
0\end{array}$ & 0 & 0 & 0 \\
\hline ن) & 0 & 0 & 0 & 0 & 0 & $\mid \begin{array}{l}\bar{\infty} \\
m \\
0 \\
0\end{array}$ & 0 & 0 & 0 \\
\hline 方 & 0 & 0 & 0 & 0 & 0 & $\begin{array}{l}\tilde{N} \\
\infty \\
\infty \\
E\end{array}$ & 0 & 0 & 0 \\
\hline 중 & 0 & 0 & 0 & 0 & 0 & 0 & 0 & \begin{tabular}{l}
$\infty$ \\
$\infty$ \\
\hdashline \\
\hdashline
\end{tabular} & 0 \\
\hline 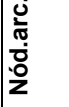 & 0 & 0 & 0 & 0 & 0 & 0 & $\begin{array}{l}\frac{\infty}{\alpha} \\
\stackrel{\infty}{m}\end{array}$ & 0 & 0 \\
\hline $\begin{array}{l}\text { on } \\
\frac{0}{0} \\
x \\
.0\end{array}$ & 0 & 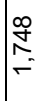 & $\stackrel{m}{\infty}$ & $\begin{array}{l}\mathfrak{N} \\
\infty \\
\end{array}$ & 0 & $\begin{array}{l}\bar{\infty} \\
\text { m } \\
0 \\
0\end{array}$ & 0 & 0 & 0 \\
\hline 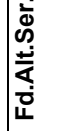 & $\begin{array}{c}\widetilde{N} \\
\text { ల్ } \\
0 \\
0\end{array}$ & 0 & 0 & 0 & 0 & 0 & 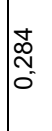 & " & 0 \\
\hline 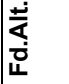 & 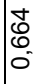 & 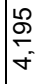 & 0 & $\begin{array}{l}\hat{\beta} \\
\tilde{O} \\
0\end{array}$ & ๙ু & $\stackrel{\infty}{\circ}$ & $\underset{\sim}{\stackrel{\sim}{\sim}}$ & 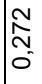 & 0 \\
\hline 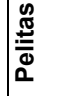 & 0 & 0 & 0 & 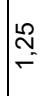 & 0 & $\begin{array}{l}0 \\
\frac{0}{\infty} \\
\infty \\
m\end{array}$ & 0 & 0 & 0 \\
\hline & $\begin{array}{l}\mathscr{8} \\
\text { ه } \\
\text { ó }\end{array}$ & 0 & 0 & 0 & 0 & $\stackrel{L}{\stackrel{8}{5}}$ & $\begin{array}{l}\text { D } \\
\text { N } \\
0 \\
0\end{array}$ & 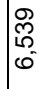 & $\begin{array}{l}\mathscr{0} \\
0 \\
0 \\
0\end{array}$ \\
\hline 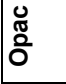 & 0 & 0 & लि & 0 & $\begin{array}{l}0 \\
\text { d } \\
0 \\
0\end{array}$ & 0 & 0 & ה & 0 \\
\hline 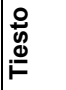 & $\begin{array}{l}\mathscr{8} \\
\stackrel{-}{F}\end{array}$ & $\mid \begin{array}{l}\mathscr{8} \\
0 \\
0 \\
0\end{array}$ & 0 & $\begin{array}{l}\hat{\tilde{m}} \\
\tilde{m} \\
\tilde{m}\end{array}$ & $\begin{array}{l}\hat{8} \\
\text { Oे } \\
\dot{\sigma}\end{array}$ & 0 & $\stackrel{N}{\stackrel{N}{N}}$ & 0 & "ָָ \\
\hline 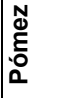 & 0 & 0 & $\begin{array}{l}\bar{\delta} \\
\text { m } \\
\stackrel{+}{*}\end{array}$ & 0 & 0 & 0 & 0 & 0 & 0 \\
\hline$\frac{\text { ठ் }}{\ddot{0}}$ & $\begin{array}{l}\mathbb{N} \\
\text { m } \\
\text { లె }\end{array}$ & 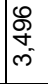 & $\mid \begin{array}{c}\hat{m} \\
m \\
0 \\
0\end{array}$ & $\stackrel{\stackrel{N}{\sim}}{\stackrel{m}{m}}$ & $\begin{array}{l}\tilde{\alpha} \\
\tilde{\alpha} \\
\tilde{\delta}\end{array}$ & $\begin{array}{l}\mathscr{0} \\
0 \\
0 \\
0\end{array}$ & $\begin{array}{l}\stackrel{\mathcal{N}}{\mathbf{N}} \\
\mathfrak{N}\end{array}$ & "ָ & 0 \\
\hline$\frac{8}{0}$ & 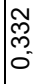 & $\stackrel{\infty}{\infty}$ & $\begin{array}{l}\Omega \\
0 \\
0 \\
0 \\
0\end{array}$ & 0 & 0 & $\begin{array}{l}0 \\
0 \\
0 \\
0\end{array}$ & $\begin{array}{l}0 \\
\infty \\
\infty \\
0 \\
0\end{array}$ & $\mid \begin{array}{l}1 \\
\infty \\
0 \\
0\end{array}$ & $\begin{array}{l}\hat{N} \\
\infty \\
N\end{array}$ \\
\hline 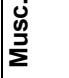 & ల్ల్ల & 0 & 0 & 0 & 0 & 0 & $\begin{array}{l}\mathscr{E} \\
\ddot{\sigma} \\
\mathscr{-}\end{array}$ & ָָ & 0 \\
\hline$\stackrel{\dot{0}}{\mathbf{0}}$ & స్ల్లె & $\begin{array}{l}\infty \\
\infty \\
m \\
m\end{array}$ & $\stackrel{m}{\stackrel{m}{\sigma}}$ & 糹 & $\begin{array}{l}0 \\
0 \\
\text { ల̃ } \\
0\end{array}$ & 0 & 0 & & $\mid \begin{array}{l}18 \\
\infty \\
0 \\
0\end{array}$ \\
\hline Oे & $\begin{array}{l}\infty \\
\infty \\
\infty \\
\infty \\
m\end{array}$ & $\stackrel{\infty}{\stackrel{\infty}{\stackrel{\infty}{*}}}$ & \begin{tabular}{|l}
$\hat{0}$ \\
0 \\
$i s$
\end{tabular} & مי & $\begin{array}{l}0 \\
\stackrel{2}{N}\end{array}$ & $\stackrel{L}{\stackrel{2}{*}}$ & $\begin{array}{l}\stackrel{8}{2} \\
\underset{N}{N}\end{array}$ & $\stackrel{\approx}{\approx}$ & 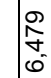 \\
\hline : & 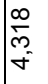 & 乏 & 玄 & $\begin{array}{l}\hat{0} \\
\tilde{O} \\
0 \\
0\end{array}$ & $\begin{array}{l}8 \\
0 \\
0 \\
0 \\
0\end{array}$ & $\begin{array}{l}\infty \\
\stackrel{\infty}{F}\end{array}$ & $\frac{\infty}{\stackrel{\infty}{\infty}}$ & 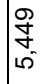 & $\underset{\substack{N \\
N}}{\mathbb{N}}$ \\
\hline 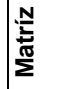 & $\begin{array}{l}\bar{N} \\
\underset{N}{N}\end{array}$ & \begin{tabular}{|l}
$\hat{0}$ \\
$\infty$ \\
$\tilde{\infty}$ \\
$\infty$
\end{tabular} & $\mid \begin{array}{l}\bar{\infty} \\
\infty \\
\infty \\
\infty\end{array}$ & $\begin{array}{l}\hat{\infty} \\
\infty \\
\infty \\
\infty\end{array}$ & $\begin{array}{l}\infty \\
0 \\
0 \\
\infty \\
\infty\end{array}$ & \begin{tabular}{l}
$\hat{0}$ \\
$\mathbb{N}$ \\
\hdashline 8 \\
0
\end{tabular} & $\begin{array}{l}\text { 早 } \\
\text { 出 } \\
\text { in }\end{array}$ & 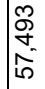 & $\mid \begin{array}{l}\overline{5} \\
8 \\
0 \\
0\end{array}$ \\
\hline$\stackrel{\circ}{\mathbf{z}}$ & $\hat{N}$ & $\stackrel{\infty}{\sim}$ & ని & ి్లి & $\bar{m}$ & $\tilde{m}$ & $\stackrel{m}{m}$ & ষ্ল & 足 \\
\hline
\end{tabular}

Tabla 6. Datos cuantificados definidos para Gualfín a partir de las caracterizaciones petrográficas.

Table 6. Quantified data defined for Gualfín based on petrographic characterizations.

(sensu Baldini y Sprovieri 2009), de pastas finas y muy finas, texturas compactas y porosas, fina y media. Los fragmentos de estilo Belén comparten similitudes técnicas con otros del valle de Hualfín y Antofagasta de la Sierra (Puente 2012b, Pérez 2013).

Estos primeros estudios de pastas nos indican que no es posible asociar de manera directa elecciones de materia prima y técnicas con forma y estilo cerámico ya que observamos una diversidad de formas de preparación de pastas. Es el caso, por ejemplo, del estilo SM donde existe variabilidad de pastas y diferencia en la proporción de agregados. Si bien no podemos señalar una preparación diferencial de pastas relacionada con las formas de las piezas, si se destaca, en el caso de las piezas cerradas, una variedad mayor que en las abiertas. Observamos también que, en algunos casos, hubo una elección de las materias primas relacionada con las actividades en las que participaban algunas piezas. Por ejemplo, en el caso de aquellas que estuvieran expuestas continuamente al fuego, como vasijas de manufactura tosca asociadas a actividades culinarias o piezas para la producción de objetos de metal registradas en los recintos bajos de Tacuil ${ }^{17}$.

\section{Consideraciones finales}

La muestra alfarera analizada responde, en su mayoría, a estilos propios del Tardío local. Los análisis petrográficos realizados permitieron observar una mayor variabilidad en la manufactura de la alfarería en el asentamiento de Tacuil. A manera de hipótesis, se ha propuesto que se trataría de una producción de alfarería local, a excepción de materiales del estilo Belén, los cuales consideramos foráneos. Como una propuesta, planteamos una posible vía de acceso a los valles altos del Calchaquí mediante la zona de Antofagasta de la Sierra, en la actual puna catamarqueña. Hasta el momento no hemos avanzado en el estudio de proveniencia de arcillas y arenas; con lo cual, a futuro, esto puede brindar nuevas herramientas para aportar al estudio de las prácticas alfareras en este sector de las quebradas altas.

Una diferencia notable entre los materiales de Tacuil y Gualfín es la escasez de cerámica de superficie pulida en los sitios del segundo. Recordemos que en Tacuil

\footnotetext{
${ }^{17}$ Se registraron aquí proporciones mayores al 30\% de inclusiones como plagioclasas, feldespatos, muscovita y cuarzo, además de litoclastos graníticos y metamórficos, feldespatos alterados y cuarzo de origen metamórfico. Inclusiones que favorecen la resistencia térmica y la dureza de las piezas.
} 
hallamos fragmentos asociados a la variedad negro pulido del Tardío (Baldini y Sprovieri 2009) y a lo que Raffino denominara como Churcal rojo pulido (Raffino 1984). En Gualfín, si bien se registraron fragmentos pulidos no corresponden al grupo Churcal pulido. Por otro lado, los escasos fragmentos asignados a la variedad negro pulido del Tardío fueron registrados principalmente en los recintos bajos de Gualfín.

Por otro lado, la aparente ausencia de sitios locales con arquitectura intrusiva inca en este sector del valle llevó a plantear aquí la posibilidad de una ocupación estatal a partir de arquitectura estatal segregada de los asentamientos locales (Villegas 2011: 78; Williams y Villegas 2013: 234). Podemos pensar en principio que, bajo este escenario, en asentamientos tardíos de las quebradas altas, por ejemplo, Tacuil, los estilos locales continuaron manufacturándose sin notables modificaciones y circulando durante momentos Incaicos y aún hasta mediados del siglo XVII. Sin embargo, es preciso recordar la presencia de fragmentos incaicos en el Fuerte de Gualfín, mencionados por Raviña et al. (1983). El hecho de que la presencia estatal se manifieste de manera escueta aquí nos plantea interrogantes que, hasta el momento, no estamos en condiciones de responder.

Esta primera caracterización sobre la alfarería de momentos Tardíos de Tacuil y Gualfín permitirá avanzar en líneas de investigación que se están abordando en el marco de los proyectos en los que se incluye esta propuesta y que tienen como objetivos, entre otros, trabajar problemáticas que aporten a los estudios de interacción, localización y uso de materias primas, producción y circulación de bienes y recursos durante los últimos momentos del Tardío prehispánico.

Salta, junio de 2019

\section{Agradecimientos}

Los trabajos fueron financiados por Wenner Gren Foundation (7923 USA); FONCyT (14425 y 01550) y CONICET (5321 y 0059). Un agradecimiento especial a la comunidad base Territorial Tacuil y Gualfín, Calixto Cruz y familia, familia Dávalos, por los permisos y el apoyo recibidos durante las tareas de campo. Al Museo de Antropología de Salta, colegas y estudiantes de la UBA y UNSa que colaboraron en los trabajos. A la Escuela de Geología de la Facultad de Ciencias Naturales de la UNSa por permitir el uso del laboratorio de microscopía. Gran parte de los datos aquí presentados es producto de los trabajos realizados por el equipo de investigación dirigido por V. Williams, a quienes se agradece haber compartido esta información, en particular a Verónica Williams y a Paula Villegas. A Mabel Mamani, por su lectura crítica y sus aportes oportunos. A los evaluadores, que ayudaron a mejorar un primer manuscrito. Ninguno de ellos es responsable de lo aquí escrito.

\section{Bibliografía}

Acuto, F.; M. Smith, \& E. Gilardengh. (2011). Reenhebrando el pasado: hacia una epistemología de la materialidad. Boletín Del Museo Chileno de Arte Precolombino, Vol. 16, (N²), 9-26.

Ambrosetti, J. B. (1899). Notas de Arqueología Calchaquí. Buenos Aires: Imprenta la Buenos Aires.

Arechaga, L. (2011). Iconografía Santamariana en el Valle Calchaquí medio y Yocavil Norte durante los Períodos de Desarrollos Regionales e Inca. (Tesis de Licenciatura en Ciencias Antropológicas, orientación Arqueología.). Facultad de Filosofía y Letras, UBA, Buenos Aires, Argentina.

Arkush, E. (2012). Los Pukaras y el Poder: Los Collas en la Cuenca Septentrional del Titicaca. In Arqueología de la Cuenca del Titicaca, Perú (L. Flores Blanco y H. Tantaleán, p. capítulo 11 295-320.). IFEA, Lima.

Baldini, L. (1980). Dispersión y cronología de las Urnas de tres cinturas en el NOA. Revista de La SAA, XIV, 49-61.

Baldini, L. (2003). Proyecto Arqueología del Valle Calchaquí Central (Salta, Argentina). Síntesis y perspectivas. In Local, regional, global: Prehistoria, protohistoria e historia en los Valles Calchaquíes (Vol. Anales Nueva Época 6, pp. 165-210). Instituto Iberoamericano, Universidad de Göteborg, Göteborg.: P. Cornell y P. Stenborg.

Baldini, L., \& Balbarrey, G. (2004). Análisis de pastas cerámicas tardías del valle Calchaquí central (Salta, Argentina). Chungara, 36, Volumen Especial, 1069-1080.

Baldini, L., \& Sprovieri., M. (2009). Vasijas negras pulidas: una variedad de la cerámica tardía del valle Calchaquí. Estudios Atacameños, 38, 21-38.

Baldini, L., \& Sprovieri, M. (2014). La especificidad de la alfarería del valle Calchaquí (Salta) en el contexto más amplio del espacio santamariano. Revista de La Escuela de Historia $N^{\circ} 13$, II (Aportes a la Arqueología del Noroeste Argentino.), 9-36.

Baldini, L., \& Villamayor, V. (2007). Espacios productivos en la cuenca del río Molinos (Valle Calchaquí, Salta). Cuadernos FHyCS - UNJu, N³2, 35-51.

Calderari, M. (1991). El concepto de estilo en Ceramología: la Tradición Estilística Santamariana en los pucos de La Paya. In El Arte rupestre en la Arqueología Contemporánea (M. Podestá, Vol. capítulo 1: 1-13). Buenos Aires: M. Podestá, M. I. Hernández Llosas y S. Renard de Coquet.

Calderari, M. (1992). Informe de beca Doctoral 
presentado al CONICET. Manuscrito.

Caviglia, S. (1985). Las urnas para niños del valle Yocavil y Calchaquí, su reinterpretación sobre una base gestáltica. Trabajo final de Seminario de Arqueología I. Manuscrito, Facultad de Filosofía y Letras, Argentina, 60 páginas.

Cigliano, E., \& Raffino, R. (1975). Arqueología en la vertiente occidental del valle calchaquí medio. Relaciones de La SAA, IX, 47-58.

Cremonte, M. B. (2001). Las pastas cerámicas como una contribución a los estudios de identidad. Actas del XIII Congreso Nacional de Arqueología Argentina. Tomo 1:99-210, Córdoba.

Cremonte, B., \& Pereyra Domingorena, L. (2013). Atlas de pastas cerámicas arqueológicas. Petrografía de estilos alfareros del NOA. (1 edición). Editorial de la Universidad Nacional de Jujuy, Facultad de Humanidades y Ciencias Sociales, Centro Regional de Estudios Arqueológicos.

Cremonte, B., \& Williams, V. (2007). La construcción social del paisaje durante la dominación inka en el NOA. In Procesos Sociales Prehispánicos en los Andes Meridionales (Editorial Brujas, Capitulo 9, pp. 207-236). Córdoba: A. Nielsen, C. Rivolta, V. Seldes, M. Velásquez y P. Mercolli (Comp.).

Dobres, M., \& Robb., J. (2005). Doing Agency: Introductory Remarks on Methodology. Journal of Archaeological Method and Theory, 12(No. 3), 159-166.

Folkes, C., Wright, H., Cas, L., De Silva, C., Lesti, C., \& Viramonte, J. (2011). A re-appraisal of the stratigraphy and volcanology of the Cerro Galán volcanic system, NW Argentina. Bulletin of Volcanology, 73, 1427-1454.

García, S., Rolandi, D., López, M., \& Valeri, P. (2002). Viajes comerciales de intercambio en el departamento de Antofagasta de la Sierra, Puna meridional argentina: pasado y presente. Redes Revista Hispana Para El Análisis de Redes Sociales, 2 ( $\mathrm{n}^{\circ 5}$ ).

Hongn, F., \& Seggiaro, R. (2001). Hoja Geológica 2566III. Cachi. Programa Nacional de Cartas Geológicas de la República Argentina. Boletín № 248. Buenos Aires.

Iucci, E. (2013). Producción, circulación y uso de cerámica tardía en el Valle de Hualfín (Catamarca, Argentina) (Tesis para optar por el grado de Doctor en Ciencias Naturales). Facultad de Ciencias Naturales y Museo, UNLP, Argentina.

Kerr, P. (1965). Mineralogía Óptica. (Editorial del Castillo). Madrid.

Lorandi, A., \& Boixadós, R. (1987, 1988). Etnohistoria de
Ios valles Calchaquíes en los siglos XVI y XVII. Runa, XVIIXVIII, 263-420.

Nielsen, A. (2007). Armas significantes: tramas culturales, guerra y cambio social en el Sur Andino prehispánico. Boletín Del Museo Chileno de Arte Precolombino, 12 (1), 9-41.

Orton, C., Tyers, P., \& Vince, A. (1997). La cerámica en Arqueología. (Crítica). Barcelona.

Páez, M. C. (2010). Persistencias y transformaciones en la composición mineral de las pastas durante el segundo milenio de la Era Cristiana en el Valle de Tafí (Tucumán). Actas del XVII Congreso Nacional de Arqueología Argentina, pp. 771-776, Universidad Nacional de Cuyo, Mendoza.

Páez, M. C., \& Arnosio, M. (2009). Inclusiones piroclásticas en pastas cerámicas del Valle de Tafí: implicancias para las prácticas de producción. Estudios Atacameños, $N^{\circ}$ 38, 5-20.

Palamarczuk, V. (2002). Análisis cerámico de sitios del bajo de Rincón Chico, Valle de Yocavil, provincia de Catamarca (Tesis de Licenciatura en Ciencias Antropológicas, orientación Arqueología). Facultad de Filosofía y letras, UBA, Argentina.

Pérez, M. (2013). Investigación sobre el Período TardíoInca en las localidades arqueológicas de Antofagasta de la Sierra (Puna Sur) y Cuenca del Río Doncellas (Puna Norte): una aproximación a través de la cerámica (Tesis para optar al grado de Doctor de la Universidad de Buenos Aires. Área Arqueología.). Facultad de Filosofía y Letras, UBA, Argentina.

Pollard, G. (1983). Nuevos aportes a la prehistoria del valle Calchaquí. Noroeste argentino. Estudios de Arqueología. Museo Arqueológico de Cachi, N³ y 4, 71-92.

Puente, V. (2012a). Prácticas de producción alfarera durante el tardío prehispánico en el valle del Bolsón. Un aporte desde la tecnología Cerámica del sitio El Duraznito (Belén, Catamarca, Argentina). Revista Arqueología, 18, 101-129.

Puente, V. (2012). Lo que "oculta" el estilo: materias primas y modos de hacer en la alfarería Belén. Aportes desde la petrografía de conjuntos cerámicos del valle del Bolsón (Belén, Catamarca, Argentina). Estudios Atacameños, No43 (2012b), 71.

Raffino, R. (1984). Excavaciones en el Churcal (Valle Calchaquí; Rep. Argentina). Revista Del Museo de La Plata, Tomo VIII No 59, 223-263.

Raffino, R., \& Baldini, L. (1983). Sitios arqueológicos del 
Valle Calchaquí Medio (Departamentos de Molinos y San Carlos). Estudios Arqueológicos, No 3, 26-36.

Raviña, M. G., lácona, A., \& Albornoz, A. M. (1983). Nota preliminar sobre una nueva fortaleza en el Valle Calchaquí: el Pukara de Gualfín. Presencia Hispánica En La Arqueología Argentina, 2(Museo Regional de Antropología e Instituto de Historia, Facultad de Humanidades, Universidad del Nordeste.), 863-874.

Roux, V. (2011). Anthropological interpretation of ceramic Assemblages: foundations and implementations of technological analysis Archaeological Ceramics: A review of current research. BAR International Series 2193. England.

Ruiz, M., \& Albeck, M. E. (1997). El fenómeno pukara visto desde la puna jujeña. Estudios Atacameños, 12, 83 - 95.

Serrano, A. (1976). Manual de la cerámica indígena (Tercera Edición) (Assandri). Córdoba.

Sprovieri, M. (2014). La circulación interregional en el valle Calchaquí (Provincia de Salta, Noroeste argentino): una visión integral desde nuevas y viejas evidencias. Revista Española de Antropología Americana, 44, núm. 2, 337-366.

Tarragó, M. (2000). Chacras y pukara. Desarrollos sociales Tardíos. In Los pueblos originarios y la conquista. Nueva Historia Argentina (Vol. I, p. capítulo 7: 257-300). Buenos Aires.: Editorial Sudamericana.

Vasvari, V. (2014). Evidencias de ocupación incaica en Payogastilla. Sector sur del valle Calchaquí (Tesis de Licenciatura en Antropología). Facultad de Humanidades, Universidad Nacional de Salta, Argentina, 193 páginas.

Villegas, M. P. (2011). Paisajes en movimiento. El uso del espacio durante los Períodos de Desarrollos Regionales e Inca en el valle Calchaquí medio (Salta, Argentina). Revista Estudios Sociales Del NOA, 11, 63-82.

Villegas, M. P. (2014). Del valle a la puna: articulación social y económica entre los poblados prehispánicos
Tardíos y los asentamientos inkas en la quebrada de Angastaco (valle Calchaquí medio, Salta) (Tesis para optar al grado de Doctor de la Universidad de Buenos Aires. Manuscrito). Facultad de Filosofía y letras, UBA, Argentina.

Williams, V. (2010). El uso del espacio a nivel estatal. In El habitat prehispánico. Arqueología de la arquitectura y de la construcción del espacio organizado (Ediunju, Vol. sección I, pp. 77 - 114). San Salvador de Jujuy.: Albeck, C. Scattolin y A. Korstanje.

Williams, V. (2019). Nuevos datos sobre las Quebradas altas del Calchaquí medio, Salta, noroeste de Argentina (NOA). Reproducción local entre los siglos XI a XV. Revista del Museo de La Plata, Volumen 4, Número 1, 183-208.

Williams, V., Villegas, M. P., Gheggi, S., \& Chaparro, M. G. (2005). Hospitalidad e intercambio en los valles mesotermales del Noroeste Argentino. Boletín de La PUCP, 9, 335-373.

Williams, V., Korstanje, M. A., Cuenya, P., \& Villegas, M. P. (2010). La dimensión social de la producción agrícola en un sector del Valle Calchaquí Medio. In Arqueología de la Agricultura: Casos de Estudio en la Región Andina Argentina (Editorial Magna, capítulo 8: 178 - 207). Tucumán, Argentina.: A. Korstanje y M. Quesada (Eds.).

Williams, V., \& Villegas, M. P. (2013). Colonización estatal en las cuencas de Angastaco- Molinos (Salta, Argentina). In Al borde del Imperio. Paisajes sociales, materialidades y memoria en áreas periféricas del noroeste argentino (Publicaciones de la SAA, Vol. capítulo 9, pp. 221-251). Buenos Aires, Argentina: V. Williams y B. Cremonte (Comp.).

Zagorodny, N., Volzone, C., \& Morosi, M. (2010). Estudio petrográfico y microtextural de la cerámica Belén procedente de contextos arqueológicos de la localidad de La Ciénaga y áreas aledañas. In Aldeas protegidas, conflicto y abandono. Investigaciones arqueológicas en La Ciénaga (Catamarca, Argentina) (Editorial Al Margen, Vol. capítulo 1, pp. 47-82). La Plata, Argentina.: B. Balesta y N. Zagorodny (Eds.). 